\title{
O Espaço Museal e a modelagem na educação: Possibilidades para alfabetização científica
}

\author{
Rosana Maria Luvezute Kripka \\ Professora, UPF \\ rkripka@upf.br
}

\author{
Danusa de Lara Bonotto \\ Professora, UFFS \\ danusabonotto@hotmail.com
}

\section{Luciana Richter}

Professora, UFSM

lurichter@gmail.com

\author{
Isabel Cristina Machado de Lara \\ Professora, PUCRS \\ isabel.lara@pucrs.br
}

\section{José Luis Schifino Ferraro}

Professor, PUCRS

jose.luis@pucrs.br

\section{Resumo}

Este artigo apresenta um processo investigativo que visou identificar como uma proposta interdisciplinar de ensino pode potencializar a alfabetização científica. A atividade, com tema 'Transportes e Fontes de Energia', foi fundamentada na função pedagógica do espaço museal e nos princípios da Modelagem na Educação. A pesquisa é de natureza qualitativa, realizada com estudantes do Ensino Médio. Por meio de dois questionários foram coletados dados, analisados com base no método da Análise Textual Discursiva. Evidencia a emergência de duas categorias: conhecimento; expressão conceitual. Identifica que a atividade propiciou reconstrução, ampliação e integração de conhecimentos, além de reflexões críticas e conscientes sobre a importância do uso do critério ambiental para escolha de combustíveis, além dos critérios de economia e rendimento. Defende que as atividades desenvolvidas possibilitaram formação crítica e aprimoramento de conhecimentos, favorecendo decisões mais conscientes e responsáveis evidenciadas por meio da resolução crítica e consciente dos problemas contextualizados.

Palavras-chave: Alfabetização Científica. Interdisciplinaridade. Museu Interativo. Modelagem na Educação.

\section{The Museum space and the modeling in education: Possibilities for scientific literacy}




\begin{abstract}
This paper presents an investigative process that aimed to identify as an interdisciplinary teaching proposal can enhance scientific literacy. The activity, considering the theme "Transport and Energy Sources', was based on the educational function of the museum space and the principles of Modeling in Education. The research is of a qualitative nature, carried out with high school students. Through two questionnaires, data were collected, which were analyzed based on the method of Textual Analysis of Discourse. Evidences the emergence of two categories: knowledge; conceptual expression. Identifies that the activity propitiates reconstruction, expansion and integration of knowledge, as well allowed as critical and conscious reflections on the importance of environmental criteria used for selection of fuels, in addition to the criteria of economy and performance. Advocates that the activities have enabled critical training and improvement of knowledge, favoring more conscious and responsible decisions, by solving critical and conscious of contextualized problems.
\end{abstract}

Keywords: Scientific Literacy. Interdisciplinarity. Interactive Museum. Modeling in Education.

\title{
Introdução
}

As orientações dos documentos oficiais da Educação, como as Diretrizes Curriculares Nacionais para o Ensino Médio - DCNEM (2012), sinalizam para a realização de práticas escolares interdisciplinares, integrando disciplinas e considerando a pesquisa como atitude cotidiana em sala de aula. Nesse contexto, torna-se necessário (re)pensar e transformar as práticas educativas de modo que os estudantes se tornem sujeitos interativos no processo de ensino e de aprendizagem, com capacidade de avaliar e interferir no contexto em que vivem, que possam ser, portanto, alfabetizados cientificamente. Por alfabetização científica, entende-se, segundo Chassot (2000, p. 19), “[...] o conjunto de conhecimentos que facilitariam aos homens e mulheres fazer uma leitura do mundo onde vivem".

Nesse sentido, a Modelagem Matemática na Educação - Modelação, entendida por Biembengut (2014) como um método de ensino com pesquisa, aliada à função pedagógica do museu, considerada por Nascimento (2007) como uma instituição voltada à popularização da ciência e da tecnologia, pode ser um caminho para propiciar aos estudantes aprendizagens com maior significado, favorecendo a alfabetização científica.

O presente estudo teve como objetivo compreender como o desenvolvimento de uma proposta interdisciplinar de ensino, centrada na temática 'Transportes e Fontes de Energia', fundamentada na função pedagógica do espaço museal e nos princípios da Modelagem na Educação, pode potencializar a alfabetização científica dos estudantes. Para tanto, elaborou-se uma proposta constituída por atividades em espaços formais (sala de aula) e não formais (Museu de Ciência e Tecnologia da Pontifícia Universidade Católica do Rio Grande do Sul - MCT-PUCRS) que teve como objetivo promover uma melhor compreensão da realidade, potencializar o desenvolvimento de uma postura crítica em relação aos tipos de transportes utilizados, das fontes 
geradoras de seus combustíveis e, ainda, possibilitar reflexões sobre os impactos ambientais de suas escolhas.

Este texto apresenta considerações teóricas sobre: Modelagem na Educação - Modelação de Biembengut (2004, 2014), interdisciplinaridade segundo Fazenda (2013), ideias do Educar pela pesquisa de Demo (2000) e Alfabetização Científica de Chassot (2000, 2003), Lorenzetti e Delizoicov (2001).

Posteriormente, apresenta-se a perspectiva metodológica da pesquisa contendo a caracterização dos sujeitos, o instrumento utilizado para a constituição dos dados, bem como o método de análise: Análise Textual Discursiva (ATD) segundo Moraes e Galiazzi (2011).

$\mathrm{Na}$ sequência são apresentados os principais resultados obtidos e as considerações sobre o estudo desenvolvido.

\section{Pressupostos teóricos da pesquisa}

O planejamento da proposta realizou-se a partir de dois pilares: Modelagem na Educação; Museu Interativo. Ao propor parte da execução da proposta em um espaço não formal, buscou-se por possibilidades para interdisciplinaridade, pesquisa e alfabetização científica.

\section{Modelagem na Educação}

A Modelagem Matemática (MM) tem se destacado nas últimas décadas, segundo Biembengut (2014), como método de ensino e de pesquisa que contribui para o ensino e aprendizagem de Matemática. Esse método possibilita ao estudante aprender matemática de modo integrado às outras áreas do conhecimento, em especial, àquela que o estudante apresenta interesse.

Para Biembengut (2014, p.21), a “[...] Modelagem é o processo utilizado na elaboração de um modelo de qualquer área do conhecimento". É por excelência, um processo de pesquisa. A adaptação desse processo para o ensino de matemática na Educação formal a autora denomina de Modelação Matemática.

Os procedimentos da Modelagem na Educação são agrupados em três fases, não disjuntas, denominadas de: a) percepção e apreensão; b) compreensão e explicitação; e c) significação $e$ expressão (BIEMBENGUT, 2014).

A utilização da Modelagem no ensino favorece o estudo e a discussão, não apenas de conteúdos matemáticos, mas também de ideias não matemáticas. Dessa forma, proporciona ao aluno "[...] valores culturais e alguns princípios gerais concernentes ao papel dele como pessoa responsável pela realidade que o cerca" (BIEMBENGUT, 2012, p. 37). 
Para Chassot (2003), se faz alfabetização científica quando o ensino da Ciência contribui para a compreensão de conhecimentos, procedimentos e valores que permitem aos estudantes tomar decisões e perceber as utilidades da ciência e de suas aplicações, tanto na melhora da qualidade de vida, quanto às limitações e consequências de seu desenvolvimento.

Diante do exposto, acredita-se que o uso da Modelagem, para tratar do tema 'Transportes e Fontes de Energia', possibilita ações reflexivas de ensino e aprendizagem, as quais contribuem com o processo de alfabetização científica.

\section{Museu Interativo: possibilidades para interdisciplinaridade, pesquisa e alfabetização científica.}

As demandas do atual contexto social, histórico e cultural exigem que as pessoas tenham um papel cada vez mais ativo na sociedade e assumam posturas mais reflexivas, críticas e argumentativas. Nesse sentido, segundo Demo (2000), a pesquisa como atitude cotidiana na sala de aula potencializa o desenvolvimento da consciência crítica e o saber intervir na realidade de modo alternativo com base na capacidade questionadora.

A utilização do Museu, entendido segundo ICOM (Conselho Internacional de Museus), como uma instituição " [...] permanente, a serviço da sociedade e de seu desenvolvimento, e aberta ao público, que adquire, conserva, pesquisa, divulga e expõe, para fins de estudo, educação e divertimento, testemunhos materiais do povo e de seu ambiente" tem grande potencial educativo, à medida que possibilita o contato dos indivíduos com materiais organizados de forma a disponibilizar acesso aos conhecimentos científicos.

Segundo Soares e Silva (2013, p.177), “[...] os museus interativos de ciências representam um espaço educativo complementar à educação formal, possibilitando a ampliação e a melhoria do conhecimento científico de estudantes, bem como, da população em geral”.

Assim, pode-se dizer que ao utilizar o espaço museal criam-se condições para uma prática interdisciplinar e contextualizada. No contexto educacional o termo interdisciplinaridade é polissêmico. Para Fazenda (2013, p. 20), “[...] o pensar interdisciplinar parte do princípio de que nenhuma forma de conhecimento é em si mesma racional. Tenta, pois, o diálogo com outras formas de conhecimentos, deixando-se interpenetrar por elas”. Assim, a interdisciplinaridade pressupõe integração entre as disciplinas e esta é alcançada quando os conhecimentos de "[...] várias disciplinas são utilizadas para resolver um problema ou compreender um determinado fenômeno sobre diferentes pontos de vista" (TOMAZ E DAVID, 2008, p. 16).

Segundo Chassot (2003, p. 91), “[...] ser alfabetizado cientificamente é saber ler a linguagem em que está escrita a natureza. É um analfabeto científico aquele incapaz de uma leitura do universo." 
Dessa forma, apresenta-se uma proposta interdisciplinar, desenvolvida em espaços formais e não formais de educação, envolvendo o tema 'Transportes e Fontes de Energia'. A proposta visou potencializar o desenvolvimento da postura crítica em relação aos tipos de transporte comumente utilizados, às fontes de combustíveis disponíveis e suas fontes geradoras, de modo a possibilitar reflexões críticas sobre impactos ambientais de suas escolhas, contribuindo para a alfabetização científica.

\section{Perspectivas metodológicas}

Esta pesquisa tem caráter qualitativo que, conforme Bogdan e Biklen (1994), é uma tentativa de compreender detalhadamente os significados e características de situações apresentadas pelos participantes da pesquisa. Neste estudo procura-se compreender como o desenvolvimento de uma proposta interdisciplinar de ensino, centrada na temática 'Transportes e Fontes de Energia', contribui com a alfabetização científica dos estudantes.

Os participantes foram 24 estudantes do primeiro ano do Ensino Médio de uma escola pública do Estado do Rio Grande do Sul. Destes, dezesseis são meninos e oito são meninas. A faixa etária dos mesmos está compreendida entre 14 e 19 anos.

Os dados foram constituídos por meio de dois questionários abertos: o primeiro aplicado no início do desenvolvimento da proposta (respondido por 24 estudantes), a fim de reconhecer as percepções iniciais dos estudantes sobre a temática e outro no final da realização da proposta (respondido por 19 estudantes), com o intuito de avaliar em que medida a proposta contribuiu para a alfabetização científica.

Os dados do questionário final foram analisados por meio de Análise Textual Discursiva (ATD) de Moraes e Galiazzi (2011), compreendida como um processo auto-organizado de construção de novas compreensões a respeito do fenômeno estudado.

A Análise compreendeu três etapas principais: (a) desconstrução dos textos do corpus - a unitarização, a fim de obter unidades com significado particular para a investigação; (b) o estabelecimento de relações entre os elementos unitários com sentido aproximados - a categorização; e (c) a captação do emergente em que a nova compreensão é comunicada e confirmada por meio de metatextos ou textos descritivos e interpretativos, que expressam os sentidos obtidos do processo de análise.

\section{Descrição da proposta de aprendizagem}

A proposta interdisciplinar apresentada neste artigo foi elaborada em uma disciplina de Programa strictu sensu em Educação em Ciências e Matemática, de uma Universidade privada, da região Sul 
do Brasil, e desenvolvida com estudantes da $1^{\text {a }}$ série do Ensino Médio de uma escola estadual do Rio Grande do Sul - RS, envolvendo a temática 'Transportes e Fontes de Energia'. Para a realização das atividades, foram necessárias nove horas-aula, desenvolvidas na escola, e uma manhã para a realização da visitação ao MCT- PUCRS. A proposta foi realizada com a integração dos professores de Matemática, Língua Portuguesa e Biologia da escola e desenvolvida seguindo as etapas da Modelagem na Educação - Modelação, propostas por Biembengut (2014).

a) Percepção e apreensão

Esta etapa da MM foi desenvolvida em dois ambientes: na escola; em uma visita orientada ao MCT-PUCRS. Inicialmente, buscou-se despertar o interesse dos estudantes, reconhecer os conhecimentos prévios e possibilitar reflexões sobre o tema.

Dessa forma, os estudantes foram questionados, em sala de aula sobre: a) fontes de energia; b) energias renováveis e não renováveis; c) a importância dos meios de transporte em nossa sociedade; d) a existência de alguma relação entre veículos motorizados, meio ambiente e saúde; e) os combustíveis utilizados nos meios de transporte e critérios de escolha dos mesmos; e f) quais meios de transporte são considerados poluentes e não poluentes.

Na sequência, realizou-se a visita orientada ao MCT-PUCRS. Os estudantes receberam um roteiro com oito experimentos para interagir: Ciclomotor elétrico; Usina hidrelétrica; Biocombustíveis; Aerogeradores; Gerador humano; Zen - a energia do seu cérebro; Usina Nuclear; e Motor do Carro. O intuito era que pudessem reconhecer nesses as fontes de energia, quais poderiam ser caracterizadas como renováveis e não renováveis, bem como associar os tipos de combustíveis às suas fontes geradoras e seus possíveis impactos ao ambiente, em meios de transporte normalmente utilizados em seus cotidianos.

Posteriormente, em sala de aula, os estudantes realizaram a produção de um texto sobre a visita ao MCT-PUCRS, orientados pelo professor de Língua Portuguesa. Também se realizou uma aula dialogada para sistematizar uma aproximação ao conceito de energia, suas fontes de energia, seus tipos e recursos gerados, diferenciando fontes renováveis de não renováveis. Discutiu-se também sobre os impactos ambientais - principalmente poluição - contextualizando com os experimentos do museu.

\section{b) Compreensão e explicitação}

Esta etapa da MM envolve a formulação do problema, a formulação do modelo matemático e a explicitação na resolução do problema a partir do modelo. A situação problema é traduzida, usando a linguagem matemática. Para tal, é necessário saber classificar as informações relevantes, selecionar as variáveis e símbolos que serão utilizados e descrever as relações percebidas por meio de um modelo matemático. 
O problema proposto envolveu a análise do custo do transporte para chegar até a escola, bem como dos impactos ambientes decorrentes desse. Foi formulado da seguinte forma: Quanto custa ir de casa até a escola e voltar, considerando diferentes meios de transporte? Quais impactos ambientais são decorrentes do meio de transporte escolhido?

Realizaram-se análises comparativas envolvendo custos com ônibus urbano, carros movidos a gasolina e carros movidos a etanol, para o deslocamento de suas casas até a escola. Para tanto, foram calculadas médias de preços de litros de combustíveis utilizados e rendimentos médios de carros específicos, obtidos por meio de informações trazidas por eles, relativas aos meios de transportes utilizados por suas famílias.

Além disso, a fim de avaliar os impactos ambientais, também foi apresentado aos estudantes um vídeo sobre a análise da liberação de gás carbônico durante a combustão da gasolina e do etanol, bem como da emissão de fuligem, para avaliação de qual seria o combustível mais poluente, segundo esses quesitos.

c) Significação e expressão

Nesta etapa da MM acontece a significação na interpretação da solução e validação do modelo e a expressão do processo e do resultado. Solicitou-se aos estudantes que, a partir do processo vivenciado, elaborassem argumentos mais consistentes, que expressassem os critérios para justificar a escolha do combustível.

Destaca-se que durante o desenvolvimento das três etapas, utilizou-se conhecimentos de Biologia, Matemática, Física, Química e Língua Portuguesa e que a integração dessas disciplinas potencializou uma melhor compreensão sobre o problema proposto, auxiliando sua resolução. Portanto, justifica-se a intencionalidade de um trabalho interdisciplinar, já que os referidos conhecimentos foram mobilizados e integrados a fim de compreender melhor o problema proposto.

\section{Discussão dos resultados}

A seguir, apresenta-se a discussão dos resultados. Os argumentos dos estudantes serão apresentados em itálico para diferenciá-los das citações bibliográficas.

\section{Identificação dos conhecimentos prévios dos alunos}

Os conhecimentos prévios dos estudantes referentes ao tema foram identificados no primeiro encontro, por meio do questionário respondido em grupos, em um total de oito grupos, designados de Grupo 1 ao Grupo 8.

Identificou-se que os estudantes reconhecem a importância dos meios de transporte para a sociedade, para a mobilidade da população e também para a distribuição de bens e serviços. Em 
relação à mobilidade da população, mencionam que os meios de transporte facilitam, tornando a locomoção mais rápida, e exemplificam, citando a facilidade para deslocamentos cotidianos (escola, trabalho) e de lazer (viagens). Conforme o Grupo 6: "É o transporte que possibilita para as pessoas a mobilização, o deslocamento de um lugar para o outro, não teria como por exemplo, ir para o trabalho sem algum tipo de transporte, a menos que fosse muito perto de casa." No que diz respeito à distribuição de bens e serviços, os estudantes expõem que os meios de transporte facilitam a distribuição de bens, como alimentos e vestuário, o que pode ser percebido na seguinte afirmação: "[...] porque sem transporte o mundo parava nós não teríamos o que comer, o que vestir etc [...]." (Grupo 1). Afirmam também, que os meios de transporte facilitam serviços associados à saúde, citando o atendimento por meio de ambulâncias.

Além disso, destacam que a utilização de veículos motorizados é prejudicial ao meio ambiente e à saúde. Alguns apenas citaram que os combustíveis são tóxicos ou poluentes e que fazem mal à saúde, mas a maioria não se preocupou em explicar como isso ocorre. Dois grupos, para explicar a poluição, afirmaram que "[...] a fumaça dos veículos estragam o meio ambiente." (Grupo 7) e “[...] eles soltam monóxido de carbono." (Grupo 2). Apenas um grupo explicou afirmando: "Sim, porque os veículos motorizados utilizam combustível, e o combustível libera gás carbônico quando entra em combustão o que é muito prejudicial a nossa saúde, prejudicando as vias respiratórias [...]." (Grupo 6).

Cinco grupos associaram a saúde física a caminhadas ou práticas de esportes e relacionaram o uso de veículos como uma das causas do sedentarismo. No questionário inicial os estudantes associaram os efeitos da poluição apenas ao uso dos combustíveis, mas não mencionaram que existem outros fatores que também são prejudiciais ao meio ambiente.

Também foi possível identificar que os estudantes percebem a existência de meios de transporte poluentes e não poluentes; no entanto, a maioria não explicava as diferenças entre eles, mas todos citaram exemplos. Apenas em dois grupos houve a preocupação em diferenciá-los, sendo que um grupo afirmou que "Os poluentes são todos aqueles que usam combustível fóssil como combustível, principalmente o diesel." (Grupo 5) o que pode indicar falta de conhecimento sobre os demais tipos de combustíveis poluentes. Citaram como exemplos de meios de transporte não poluentes: bicicletas, skate, patinete, patins, caiaque, cavalos, camelos, dromedários, carros elétricos, as pernas, etc. Já o Grupo 6 definiu “[...] os não poluentes são os que não liberam nenhum tipo de gás, quando ocorre a combustão [...] e todos os que não liberam substâncias.”, o que indica que apenas consideraram a poluição atmosférica, desconsiderando a poluição sonora, da água e do solo também causadas por meios de transportes. Como exemplos citaram carros, motos, caminhões, navios, helicópteros, zepelin, foguetes, naves espaciais, ônibus, balão, avião, etc. 
No que diz respeito aos critérios utilizados para a escolha do combustível, dentre os oito grupos três não responderam sobre os critérios, um disse que deveria ser o mais econômico, mas não explicou e quatro grupos indicaram que o critério seria a economia, sendo que apenas dois deles se referiram à palavra rendimento e apenas um grupo explicou o seu conceito. "Normalmente é o balanço entre preço e quantos quilômetros o carro faria com determinados litros em seu tanque, ou seja o que render mais por menos preço" (Grupo 5). Ainda desses quatro, dois não se referiram à palavra rendimento, mas usaram a palavra desenvolvimento. Afirmaram que o critério seria o combustível que "[...] o carro se adapta melhor ou se desenvolve melhor." (Grupo 3), e o outro "[...] com o tipo de combustível que o carro desenvolva melhor." (Grupo 6). Além disso, apenas um dos grupos apontou, além destes dois critérios, que é necessário considerar a poluição causada ao meio ambiente, mas não explicou.

As respostas dos estudantes evidenciam que estes possuem conhecimentos prévios sobre o que são fontes de energia renovável e não renovável, mas não tem clareza sobre seus conceitos, visto que alguns vincularam a definição ao uso. Alguns, ainda, definiram energias renováveis como aquelas que podem ser reutilizadas, enquanto outros, como as que podem ser utilizadas mais de uma vez. Percebe-se aqui, que há um equívoco conceitual que emprega gasto energético, na tentativa de referirem-se às fontes de energia. Já a definição de não renováveis em relação ao uso, relaciona-se ao que não se pode reutilizar e ao que não se pode refazer após o uso.

Também houve a tentativa de diferenciar as fontes de energia com exemplos, ao invés de conceituação. Eles citaram como renováveis a energia solar, a elétrica, a água, a hidrelétrica e a eólica e como não renováveis a gasolina, o álcool, o gás, o diesel e os combustíveis fósseis. Nessa diferenciação nota-se o equívoco em classificar o álcool como não renovável e também a falta de clareza de quais são as fontes de energias e os tipos de energia e recursos enérgicos produzidos por meio delas.

Além disso, os estudantes também relacionaram fontes de energia à transformação. Dessa forma, as renováveis foram definidas como as que se transformam em outras e as não renováveis como as que não se transformam.

\section{O que revela a ATD após a realização da atividade?}

Analisando as respostas, emergiram duas categorias que possibilitam discutir como a proposta desenvolvida contribuiu para a alfabetização científica dos estudantes. As categorias são: conhecimentos; expressão conceitual. A seguir, descrevemos as categorias, fundamentando-as teoricamente e ancorando-as nos argumentos dos sujeitos. 


\section{Categoria 1: Conhecimentos}

Nessa categoria notou-se que o desenvolvimento da proposta possibilitou a ampliação do conhecimento dos estudantes, à medida que estes evidenciaram que passaram a conhecer ou reconhecer novas fontes de energia, bem como aprenderam a calcular custos de combustíveis, desempenho para o automóvel e avaliação da poluição, a partir de carros e combustíveis particulares, considerados para análise. Além disso, percebeu-se que a proposta favoreceu a integração de conhecimentos, possibilitando tomada de decisões responsáveis e conscientes, instigando para mudança de hábitos e preservação da saúde e meio ambiente.

No que tange a ampliação do conhecimento dos estudantes, destacam-se excertos de três estudantes:

[...] sempre que pensamos em fontes de energia automaticamente vem na nossa mente o combustível, a gasolina e o álcool, mas existem outras muito importantes. $\mathrm{O}$ sol, o ar, energia nuclear [...] a água, entre outras. [...] Aprendi também a verificar o que vale mais a pena se é o álcool ou a gasolina e a calcular os preços dos combustíveis. (Estudante E3)

A visita ao museu foi muito boa para ampliar o conhecimento sobre as fontes de energia, a água, sol, usinas etc. (Estudante E4)

No sentido que possamos ver quais são mais poluentes, outras formas de fontes de energia que eu nem sabia que existiam: a das marés, a de massa e através das ondas também e como todas as pessoas acham que a energia nuclear em si não é poluente, mas a forma de descarte das varetas que é o poluente. (Estudante E15)

As expressões dos estudantes - descritas anteriormente - permitem inferir que o desenvolvimento da atividade contribuiu para a ampliação do conhecimento dos estudantes, em relação às fontes, tipos de energia e ao custo dos combustíveis. Conforme sinalizam Lorenzetti e Delizoicov (2001, p. 11),

Durante as visitas aos museus, e as outras formas de saídas a campo, atividades práticas, os alunos aprendem por meio da interação que se estabelece com os professores, com os adultos, contando com a disposição de objetos e com a relação entre experiência e o seu conhecimento. Desta forma, ao retornarem à escola, os professores ao sistematizarem este conhecimento possibilitam o seu aprofundamento e a construção de outros saberes. A sistematização dos conhecimentos é, portanto, uma das tarefas fundamentais da escola e da atuação docente para que este processo de alfabetização ocorra, de modo a propiciar significado e sentido ao conhecimento que está sendo apropriado pelo aluno.

No que diz respeito à integração de conhecimentos, para Chassot (2003) quando se propicia aos estudantes uma formação crítica, ajudando-os a perceberem que a ciência pode ser útil para a melhoria de suas qualidades de vida, que lhe permita tomar decisões conscientes, está se propiciando a alfabetização científica. Nesse contexto, os estudantes expressam: 
Agora eu entendo quase tudo sobre preços e distâncias, eu pensava que valia mais apena vir de carro para a escola, depois dessas aulas eu aprendi que vale mais a pena vir de ônibus. (Estudante E7)

Aprendi mais sobre energias renováveis que são energia do corpo e solar e nãorenováveis que são energia elétrica, etc..., eu também aprendi muito sobre ônibus, carro etanol, carro gasolina que se referem ao transporte entre eles qual deve andar depende sempre da distância e o rendimento do automóvel, aprendi também qual combustível polui mais, e depois de uma experiência chegamos na conclusão que a gasolina polui mais porque após ela ser esquentada ou seja aquecida ela produz fuligem que é um resíduo tóxico e ruim para o meio ambiente e o etanol é menos poluente. (Estudante E18)

No depoimento do estudante E18, destaca-se a atribuição de significado próprio aos conceitos científicos, ao manifestar que a gasolina após ser "[...] aquecida ela produz fuligem”, reportando-se ao conceito do processo de combustão da gasolina e do etanol, apresentados no vídeo apresentado em sala de aula ${ }^{1}$.

Para Lorenzetti e Delizoicov (2000, p. 122) a alfabetização científica está condicionada ao fato de o estudante "[...] refletir criticamente, posicionar-se e tomar decisões sobre questões locais e globais, em que o conhecimento estará aliado às atitudes e às habilidades necessárias para compreender o mundo". Na mesma perspectiva, Chassot (2003) aponta para a necessidade de um ensino impregnado de posturas mais holísticas, que contemple aspectos históricos, dimensões ambientais e posturas éticas e políticas.

Nesse sentido, verificou-se que o estudante E9 manifestou que levaria em consideração para o abastecimento de um automóvel "o preço, pois hoje em dia a vida não está fácil, mas ajudar o meio ambiente é importante para a vida na terra continuar por muitos e muitos anos.".

Ao término das atividades, ao serem questionados sobre quais seriam os critérios a serem adotados para a escolha do combustível, ao abastecer um veículo flex, três foram claramente evidenciados: economia, rendimento e a questão ambiental, que são subcategorias relacionadas à grande categoria "conhecimentos". Foi possível identificar que, dentre 19 repostas, 14 estudantes se referiram ao critério de economia, sendo que oito se referiram ao rendimento do carro. Dos cinco restantes, dois não responderam e três se referiam apenas ao critério ambiental. Cabe lembrar que inicialmente apenas um grupo, constituído de quatro estudantes, havia mencionado o conceito específico de rendimento. Além disso, apenas um deles havia se referido à questão ambiental. Contudo, ao final das atividades, de 19 estudantes respondentes, foi possível identificar, nas respostas de 12 estudantes o critério ambiental, conforme evidencia-se, por exemplo, nas duas respostas seguintes:

\footnotetext{
${ }^{1}$ Disponível em: https://www.youtube.com/watch?v=TLAoKIDc0M0
} 
$\mathrm{Eu}$ escolheria o combustível que pudesse fazer a diferença no meio ambiente, e também levaria em consideração o preço e também não andaria muito de carro faria caminhadas e usaria meios de transporte mais sustentável. (Estudante E2)

Primeiramente escolheria o mais barato, de vista todo mundo faz isso, em segundo optaria pelo rendimento do meu carro, qual renderia melhor no meu carro [...] por último a poluição de cada um, só que sinceramente, eu nem pararia para pensar na poluição, só que, com as aulas que tive com vocês vou parar e pensar melhor mesmo. (Estudante E15)

É perceptível que seriam necessárias mais atividades reflexivas para esclarecer questões relativas à poluição. Identificou-se que dois, dentre 19 estudantes, afirmaram que o álcool não polui o meio ambiente, o que evidencia que esse conceito não foi compreendido por esses estudantes. De modo geral os estudantes integraram valores e conhecimentos para tomar decisões mais conscientes e responsáveis na vida cotidiana, de acordo com as necessidades e com o contexto.

\section{Categoria 2: Expressão conceitual}

$\mathrm{Na}$ categoria 'expressão conceitual' sobre fontes de energia, não houve avanço conceitual na diferenciação de fontes renováveis e não renováveis, pois os estudantes não mudaram as conceituações equivocadas ou alternativas que manifestaram no questionário inicial. No entanto, a maioria conseguiu exemplificar os tipos de energia gerados pelas fontes, o que demonstra a contribuição da proposta desenvolvida.

No que diz respeito às fontes de energia, segundo Pena (2015), as fontes de energia renováveis são aquelas que têm capacidade de serem repostas naturalmente e fontes de energia não renováveis as que podem esgotar-se em um futuro relativamente próximo.

Em relação à conceituação de fontes de energia, destacam-se três respostas:

Renováveis são as fontes que podem ser utilizadas mais de 1 vez. Nãorenováveis são as que é utilizada uma única vez. (Estudante E1)

Renováveis são aquelas que podemos usar novamente e não renováveis aquelas que não são mais utilizadas. (Estudante E2)

É uma energia que você pode fazer de novo e essa é a energia renovável e não renováveis é a que não pode ser feita de novo. (Estudante E5)

É perceptível que os estudantes E1 e E2 atribuem significação ao conceito de renováveis e não renováveis atrelado à quantidade de vezes que é possível a utilização. Já o estudante E5 diferencia as fontes de energia em relação à possibilidade de produção. Os estudantes não consideraram a questão dos recursos responsáveis pela produção energética para conceituar, apenas vincularam a conceituação, as palavras renováveis e não renováveis.

Já no que diz respeito à utilização de exemplos, temos: 
Renováveis são as que podem ser reutilizadas tipo água, eólica, solar, etc. As não renováveis são nuclear, combustíveis, variados do petróleo, álcool. E elas podem ser utilizadas uma vez. (Estudante E6)

Energias renováveis são energias que podem serem repostas e energias não renováveis que quando terminam somem, por exemplo, o carro é um exemplo de energia renovável, quando acaba a energia dele, ela pode ser reposta, com álcool, gasolina ou etanol. (Estudante E7)

Por meio das respostas dos estudantes E6 e E7 pode-se perceber a tentativa de diferenciar as fontes de energia utilizando a exemplificação para explicitar os conceitos. Eles citaram como renováveis a energia solar, a elétrica, a água, a hidrelétrica e a eólica e como não renováveis a gasolina, o álcool, o gás, o diesel e os combustíveis fósseis. Nessa diferenciação verifica-se o equívoco em classificar o álcool como não renovável e também a falta de clareza de quais são as fontes de energias e os tipos de energia e recursos enérgicos produzidos por meio delas. No caso do estudante E7, percebe-se a utilização do carro como exemplo, demonstrando a falta de entendimento do mesmo.

Com o desenvolvimento da proposta interdisciplinar, percebeu-se ampliação do vocabulário, visto que surgiram termos novos, que não haviam sido expostos no questionário inicial, como é o caso da molécula de ATP (Trifosfato de Adenosina), que é a forma como o corpo armazena a energia resultante da quebra da glicose. Isso se explicita na resposta do estudante E18: “Energias renováveis são aquelas que após ser usada ela pode ser reutilizada como: energia do corpo ATP, e energia solar. Energia não renováveis são aquelas que após serem usadas não podem ser reutilizadas como os fósseis, energia elétrica, etc.".

Em relação ao questionário inicial houve avanços para a maioria dos estudantes, que utilizaram exemplos pertinentes relacionados aos conceitos, conseguindo demonstrar um acréscimo tanto na quantidade de exemplos, quando na adequação dos mesmos.

Conforme D’Ambrosio (2012) o conhecimento se dá a partir da ação do conhecer sobre a realidade, decorrente de situações problemas reais. Nessa perspectiva, ao responder, por meio dos processos investigativos da modelagem o problema, Quanto custa ir de casa até a escola e voltar, considerando diferentes meios de transporte? Quais impactos ambientais decorrentes do transporte escolhido?, foi possível criar condições para que os estudantes relacionassem conhecimentos de Matemática, Química e Biologia. Além disso, nossa pretensão ao propor tal problema foi propiciar a ampliação e integração de conhecimentos, contribuindo para alfabetização científica no sentido de buscar soluções conscientes e críticas para seus problemas cotidianos, por meio de argumentações científicas. 


\section{Considerações Finais}

Este trabalho teve como objetivo o desenvolvimento de uma proposta interdisciplinar de ensino centrada no tema 'Transportes e Fontes de energia'. O planejamento da proposta teve como fundamentos as ideias da Modelagem na Educação e a função pedagógica do Museu Interativo. Procurou-se compreender em que medida o desenvolvimento da mesma promove a alfabetização científica dos estudantes.

A análise dos resultados apontou duas categorias emergentes: conhecimento; expressão conceitual. Na primeira categoria, identificou-se que a proposta possibilitou a reconstrução, ampliação e integração de conhecimentos, bem como propiciou reflexões críticas e percepções conscientes sobre a importância do uso do critério ambiental para escolha de combustíveis, além dos critérios de economia e rendimento. Assim, percebe-se que os estudantes integraram valores e conhecimentos para tomar decisões mais conscientes e responsáveis na vida cotidiana.

Na segunda categoria, não ficou explícito um avanço conceitual na diferenciação de fontes renováveis e não renováveis, visto que os estudantes não mudaram as conceituações equivocadas e/ou alternativas que apresentaram no início. No entanto, a maioria conseguiu exemplificar os tipos de energia gerados por essas fontes, o que demonstra a contribuição da proposta desenvolvida, pelo avanço tanto na quantidade de exemplos, quando na adequação dos mesmos, o que nos fez perceber a necessidade de continuar o desenvolvimento de atividades aprofundando aspectos conceituais referentes a fontes de energia renováveis e não renováveis.

\section{Referências}

BIEMBENGUT, M. S. Modelagem Matemática no Ensino Fundamental. Blumenau: EdiFurb, 2014.

.Perspectivas metodológicas em Educação Matemática: um caminho pela Modelagem e Etnomatemática. Caderno Pedagógico, Lajeado, v. 9, n. 1, p. 27-38, 2012.

BRASIL. Diretrizes Curriculares Nacionais para o Ensino Médio. Brasília: Ministério da Educação/ Conselho Nacional de Educação/Câmara de Educação Básica, 2012.

CHASSOT, A. Alfabetização científica: uma possibilidade para a inclusão social. Revista Brasileira de Educação. n. 22. jan./fev./mar./abr. 2003. p.89-100

. Para que(m) é útil o ensino? Canoas: Editora da ULBRA, 1995.

2000. Alfabetização Científica: questões e desafios para a educação. Ijuí: Editora Unijuí,

D'AMBROSIO, U. Da realidade a ação: reflexões sobre educação e matemática. São Paulo: Summus, 1986.

D’AMBRÓSIO, U. Um enfoque transdisciplinar à Educação e à História da matemática. In: BICUDO, M. A.V; BORBA, M. C. (Org.). Educação Matemática: pesquisa em movimento. 4 ed. São Paulo: Cortez, 2012. p. 13-31. 
DEMO, P. Educar pela pesquisa. 4 ed. Campinas: Autores Associados, 2000. - (Coleção educação contemporânea).

FAZENDA, I. Práticas Interdisciplinares na escola. 13. ed. São Paulo: Cortez, 2013.

FALCÃO, D. Instrumentos Científicos em museus, em busca de uma pedagogia de exibição. In: VALENTE, M.E.A. (Org.), Museus de Ciências e Tecnologia, interpretações e ações dirigidas ao público. Rio de Janeiro: MAST, 2007.

LORENZETTI, L.; DELIZOICOV, D.. Alfabetização científica no contexto das séries iniciais. ENSAIO - Pesquisa em Educação em Ciências. v. 3, n. 1, jun., p. 1- 17, 2001.

NASCIMENTO, S.S. Museus, ciência, tecnologia e sociedade: um desafio de gerações. In:

VALENTE, m.e.a (Org.), Museus de Ciência e Tecnologia, interpretações e ações dirigidas ao público. Rio de janeiro: MAST, 2007.

PENA, R. A. Fontes de Energia. Disponível em: <http://www.brasilescola.com/geografia/fontesenergia.htm>. Acesso: 30 de maio de 2015.

SOARES, C. T. S.; SILVA, A. M. M. Escolha e controle em um ambiente museal: um estudo com professores de Ciências. Investigações em Ensino de Ciências, v. 18, n. 1, p. 177-198, 2013.

TOMAZ, V. S.; DAVID, M. M. M. S. Interdisciplinaridade e aprendizagem da Matemática em sala de aula. (Coleção Tendências em Educação Matemática) - Belo Horizonte: Autêntica, 2008.

Submetido em julho de 2015 Aprovado em outubro de 2015 